\title{
Review of the Highlights of X-Ray Studies of Liquid Metal Surfaces
}

\section{Citation}

Pershan, P. S. 2014. "Review of the Highlights of X-Ray Studies of Liquid Metal Surfaces." Journal of Applied Physics 116 (22) (December 14): 222201.

\section{Published Version}

doi:10.1063/1.4902958

\section{Permanent link}

http://nrs.harvard.edu/urn-3:HUL.InstRepos:17223813

\section{Terms of Use}

This article was downloaded from Harvard University's DASH repository, and is made available under the terms and conditions applicable to Other Posted Material, as set forth at http:// nrs.harvard.edu/urn-3:HUL.InstRepos:dash.current.terms-of-use\#LAA

\section{Share Your Story}

The Harvard community has made this article openly available.

Please share how this access benefits you. Submit a story.

Accessibility 


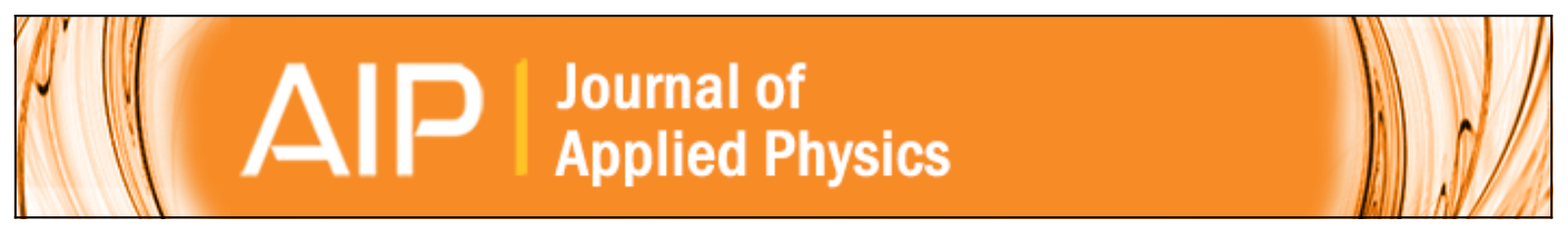

\section{Review of the highlights of X-ray studies of liquid metal surfaces}

\section{P. S. Pershan}

Citation: Journal of Applied Physics 116, 222201 (2014); doi: 10.1063/1.4902958

View online: http://dx.doi.org/10.1063/1.4902958

View Table of Contents: http://scitation.aip.org/content/aip/journal/jap/116/22?ver=pdfcov

Published by the AIP Publishing

\section{Articles you may be interested in}

Crystalline monolayer surface of liquid $\mathrm{Au}-\mathrm{Cu}-\mathrm{Si}-\mathrm{Ag}-\mathrm{Pd}$ : Metallic glass former

Appl. Phys. Lett. 98, 251915 (2011); 10.1063/1.3599515

Thermal stability of surface freezing films in Ga-based alloys: An x-ray photoelectron spectroscopy and scanning tunneling microscopy study

J. Chem. Phys. 127, 034702 (2007); 10.1063/1.2751157

Surface reaction of nitrogen with liquid group III metals

J. Chem. Phys. 114, 6353 (2001); 10.1063/1.1355984

X-ray absorption spectroscopy of liquid surface

Rev. Sci. Instrum. 68, 3307 (1997); 10.1063/1.1148289

Glass transition and atomic structures in supercooled $\mathrm{Ga} 0.15 \mathrm{Zn} 0.15 \mathrm{Mg} 0.7$ metallic liquids: A constant pressure molecular dynamics study

J. Chem. Phys. 106, 8830 (1997); 10.1063/1.473944

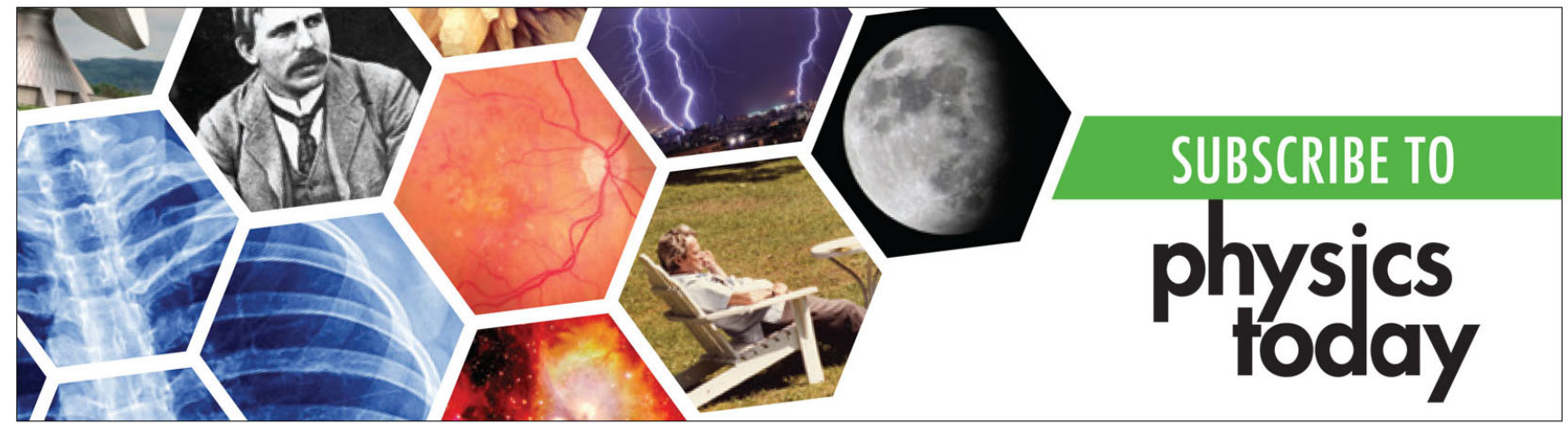




\title{
Review of the highlights of X-ray studies of liquid metal surfaces
}

\author{
P. S. Pershan \\ Department of Physics and the School of Engineering and Applied Sciences, Harvard University, Cambridge, \\ Massachusetts 02138, USA
}

(Received 27 March 2014; accepted 6 May 2014; published online 8 December 2014)

X-ray studies of the interface between liquid metals and their coexisting vapor are reviewed. After a brief discussion of the few elemental liquid metals for which the surface Debye-Waller effect is sufficiently weak to allow measurement, this paper will go on to discuss the various types of surface phenomena that have been observed for liquid metal alloys. These include surface adsorption, surface freezing, surface aggregation of nm size atomic clusters, and surface chemistry that leads to new 3D crystalline phases. (C) 2014 AIP Publishing LLC. [http://dx.doi.org/10.1063/1.4902958]

\section{INTRODUCTION}

D'Evelyn and Rice ${ }^{1-3}$ first drew attention to the fact that since liquid metals consist of charged ions suspended in a Fermi sea of conduction electrons the ion-ion interactions should be qualitatively different from the van der Waals atom-atom interactions in the vapor above the liquid surface. One consequence of this is that at the boundary between liquid and vapor neighboring atoms should form a relatively flat local surface. This has the effect that the atom-atom correlations at the surface can be described as those of a reasonably well-defined atomic layer. It is expected that this atomic layering should persist into the bulk for a distance comparable to the bulk positional correlation length, which can be a few atomic diameters long.

\section{EXPERIMENTAL STUDIES}

Surface induced atomic layering was first observed for liquid gallium ${ }^{4}$ and mercury ${ }^{5}$ using synchrotron generated $\mathrm{x}$-ray reflectivity in 1995 . Data from the measurements demonstrating this effect are shown in Fig. 1 as the ratio of the raw reflectivity $R\left(q_{z}\right)$ to the theoretical Fresnel reflectivity $R_{F}\left(q_{z}\right)$ from a flat surface between the vapor and an idealized material with a sharp flat interface that has the same bulk atomic density as the actual material. ${ }^{6}$ The reason for displaying the data in this way is that $R\left(q_{z}\right)$ falls off by many orders of magnitude as $\mathrm{q}_{\mathrm{z}}$ increases and the features that characterize the surface in Fig. 1 would hardly be visible in a plot of $R\left(q_{z}\right)$ vs. $\mathrm{q}_{\mathrm{z}}$. The peak in $R\left(q_{z}\right) / R_{F}\left(q_{z}\right)$ for $\mathrm{Ga}$ at $\mathrm{q}_{\mathrm{z}} \approx 2.5 \AA^{1}$ is caused by constructive interference between atomic layers spaced a distance $d \approx 2 \pi / 2.5 \AA \approx 2.5 \AA$. The width of the peak is a measure of the length away from the surface over which the surface induced layering decays.

The first thing to note about the two plots in Fig. 1 is that the surfaces of Ga (Ref. 4) and Hg (Ref. 5) are qualitatively different from each other. Theoretical modeling of these data shows that the surface layering for Ga decays monotonically within the expected bulk correlation length. In contrast, the amplitude of the near surface layers for liquid $\mathrm{Hg}$ exhibits a subtle structure that is responsible for the broad dip in the data near $\mathrm{q}_{\mathrm{z}} \approx 0.6 \AA^{-1}$. A plausible explanation for this effect was given by the molecular simulation analysis of
Bomont et al. ${ }^{7}$ A similar dichotomy was observed for the other elemental liquid metals that have been measured in subsequent years. ${ }^{8}$ This is discussed further in the "Discussion" section of this paper.

An unfortunate problem in studying elemental liquid metals is that for most of them a combination of high vapor pressure along with increased thermal excitations that are responsible for a type of Debye-Waller factor places limitations on the metals that can be studied. See Table 4.2 of Pershan and Schlossman. ${ }^{8}$ In the first instance, a high vapor pressure encumbers the vacuum techniques that are needed to produce atomically clean surfaces. Furthermore, it also causes both vapor deposition on the $\mathrm{x}$-ray windows and loss of sample due to evaporation.

The problem with the Debye-Waller factor is that it reduces the reflectivity for large $\mathrm{q}_{\mathrm{z}}$ in a way that limits the
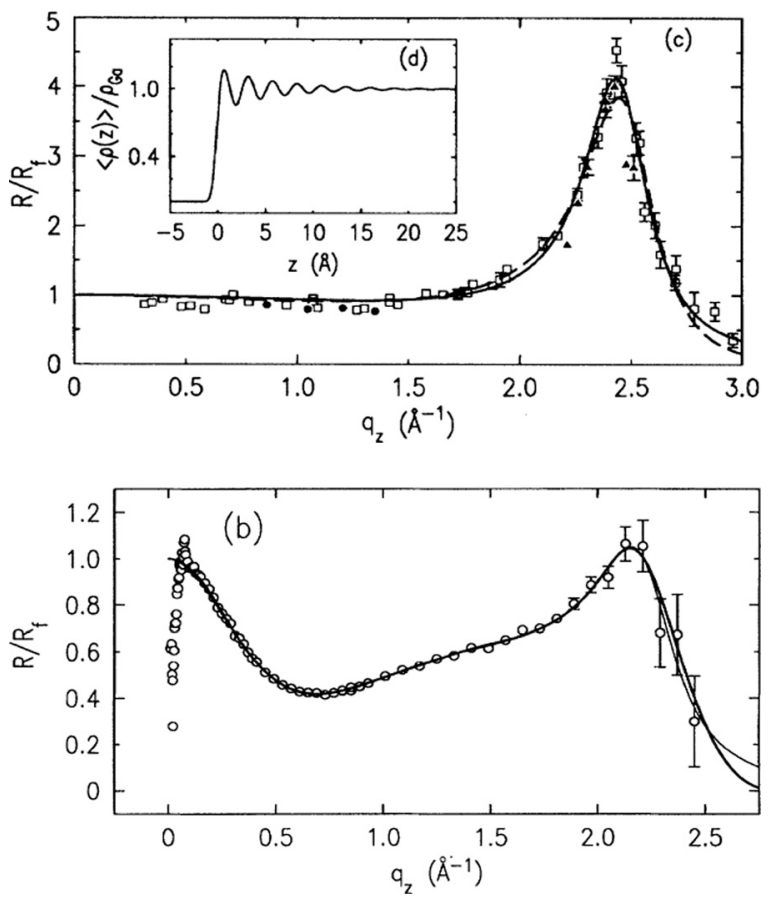

FIG. 1. Reflectivity data for liquid Ga (left) ${ }^{4}$ and liquid $\mathrm{Hg}(\text { right })^{5}$ normalized to the theoretical reflectivity from the flat surface of a liquid with the same bulk electron density as $\mathrm{Ga}$ and $\mathrm{Hg}$, respectively. 
measurable range of $\mathrm{q}_{\mathrm{z}}$ to values that can be too small to enable surface characterization. ${ }^{9}$ In general, the capillary exponent $^{8}$ by which this limitation can be expressed is $\eta=\left(k_{B} T_{m} / 2 \pi \gamma\right) q_{\text {peak }}^{2}$, where $\gamma$ is the surface tension, $\mathrm{T}_{\mathrm{m}}$ is the melting temperature of the metal, and $q_{\text {peak }}$ is the value of $\mathrm{q}_{\mathrm{z}}$ where the peak in the reflectivity occurs. For Ga and Hg q $\mathrm{q}_{\text {peak }} \approx 2.2-2.4 \AA^{-1}$. A tabulation of the liquid metals for which $\eta \leq 2.0$, which corresponds roughly to the practical limit for $\mathrm{x}$-ray reflectivity, is given by Pershan and Schlossman in Table 4.2. ${ }^{8}$ Aside from the metals already measured, $\mathrm{Ga}, \mathrm{Hg}, \mathrm{In},{ }^{10} \mathrm{~K},{ }^{11} \mathrm{Sn},{ }^{12,13}$ and $\mathrm{Bi},{ }^{13}$ Pershan and Schlossman assert that the only other elements that could be measured by these criteria are $\mathrm{Pb}, \mathrm{Li}, \mathrm{Na}, \mathrm{Al}, \mathrm{La}$, and $\mathrm{U}$. Although the table reports that Ge was a measured element the data Ge was never satisfactorily analyzed. ${ }^{14}$

The fact that the Debye-Waller corrections for liquid surfaces arise from thermal capillary waves rather than the elastic phonon modes in a crystal causes them to be much larger than is common for Bragg reflections from crystals. ${ }^{6,9}$ This is, in fact the origin of the capillary exponent discussed above. The other subtle issue encountered with liquid surfaces is that the corrections actually vary with the resolution of the measuring instrument. ${ }^{15}$ We will not go into the reason for that here; however, it is fully discussed by Pershan and Schlossman. ${ }^{8}$

The elemental metals for which reflectivity measurements have been done so far fall into two groups. The layering for the first group $\left(\mathrm{Ga},{ }^{4,9} \mathrm{In},{ }^{10}\right.$ and $\left.\mathrm{K}^{11}\right)$ appear to decay monotonically, while those of the second group $\left(\mathrm{Hg},{ }^{5,16}\right.$ $\mathrm{Sn},{ }^{12}$ and $\mathrm{Bi}^{13}$ ) have the subtle structure alluded to above for $\mathrm{Hg}$. This is further discussed below.,17

On the other hand, the number and variety of liquid metal alloys that can be studied is practically inexhaustible. For example, see Table 4.3 or Pershan and Schlossman. ${ }^{8}$ The near resonant $\mathrm{x}$-ray reflectivity from the $\mathrm{Bi}_{43} \mathrm{Sn}_{57}$ that is shown in Fig. 2 is an example of one of the phenomena that can be studied. ${ }^{18}$ According to Gibbs, the fact that $\mathrm{Bi}$ has a lower surface tension $(378 \mathrm{mN} / \mathrm{m})$ than $\mathrm{Sn}(567 \mathrm{mN} / \mathrm{m})$

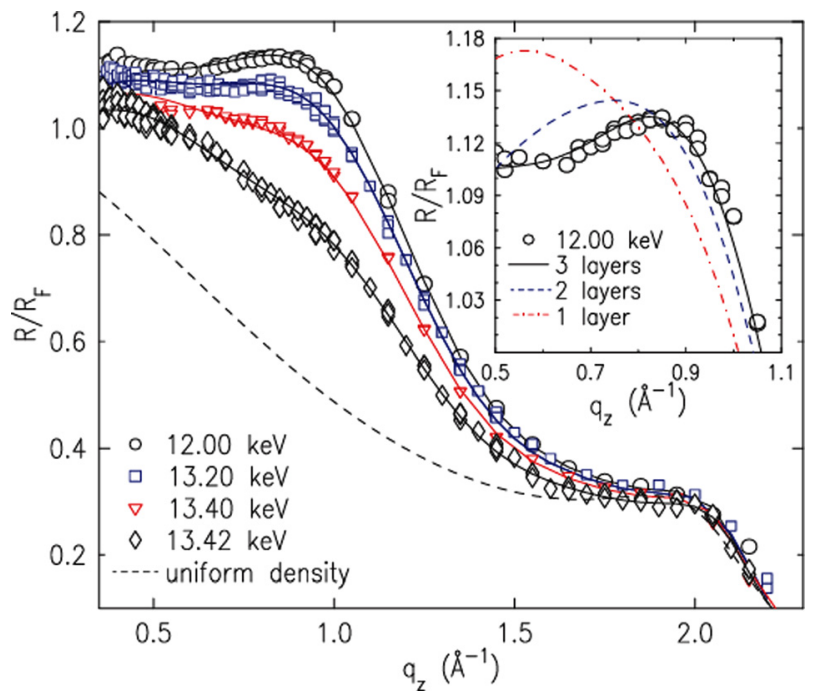

FIG. 2. X-ray reflectivity from the surface of the $\mathrm{Bi}_{43} \mathrm{Sn}_{57}$ for four different $\mathrm{X}$-ray energies in the vicinity of the $13.418 \mathrm{keV} \mathrm{Bi} \mathrm{L3}$ absorption edge. ${ }^{18}$ should cause Bi to segregate at the surface. This can be quantitatively measured by studying the reflectivity as a function of x-ray energy. For example, as a result of the dispersion in the $\mathrm{Bi}$ atomic scattering factor in the vicinity of the L3 absorption edge the scattering power of $\mathrm{Bi}$ relative to $\mathrm{Sn}$ changes with energy. From quantitative analysis, the differences in the four curves in Fig. 2 Shpyrko et al. were able to demonstrate that while the surface layer is rich in adsorbed $\mathrm{Bi}$ the second layer in rich in $\mathrm{Sn}$ and the third layer is once again rich in $\mathrm{Bi}$.

A very different surface phenomenon occurs at the surface of the liquid phase of the $\mathrm{Au}_{82} \mathrm{Si}_{18}$ eutectic. ${ }^{19,20}$ Reflectivity data for this alloy are shown in Fig. 3 for three temperatures, $635 \mathrm{~K}$ (LT), 695 (HT), and 720 (LL). ${ }^{19,20}$ Note that although the Debye-Waller factor at the temperature of the LT data, which is about $300 \mathrm{~K}$ higher than the data for Ga that is shown in Fig. 1, should reduce the reflectivity by at nearly an order of magnitude, the peak reflectivity for $\mathrm{Au}_{82} \mathrm{Si}_{18}$ is more than twice as intense as that of $\mathrm{Ga}$. Although the $\mathrm{Au}_{82} \mathrm{Si}_{18}$ reflectivity has the same type of broad minima near $\mathrm{q}_{\mathrm{z}} \approx 0.5 \AA^{-1}$ as the $\mathrm{Hg}$ data the shape of the broad shape of the peak is qualitatively different from $\mathrm{Ga}$, $\mathrm{Hg}$, and all of the other metals that have been studied. Furthermore, measurement of the temperature dependence of the reflectivity reveals abrupt reversible first order transitions between the three types of reflectivity patterns. ${ }^{20}$ These reflectivity changes are accompanied by transitions between the sharp Bragg peaks that are observed in the grazing incidence diffraction data that is shown in Fig. $4{ }^{19,20}$

From the existence of sharp Bragg peaks, along with truncation rod and reflectivity measurements, one can conclude that when the solid eutectic melts the surface is initially made up of 2D bilayer crystals. On further heating, these bilayer crystals first melt to form 2D monolayer crystals. On further heating these eventually melt to produce a liquid like surface.

Wide-angle grazing incidence diffuses scattering measurements reveal that the stiffness induced by the surface bilayer crystals quenches the short wavelength thermal capillary waves. This has the effect of diminishing the effect that

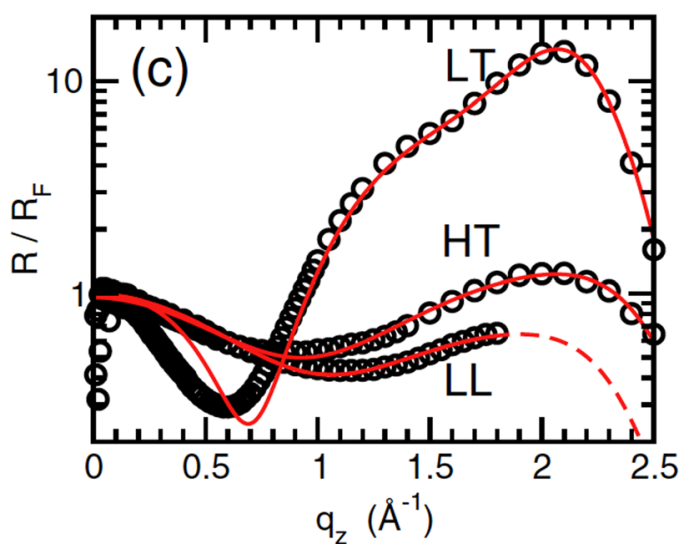

FIG. 3. The open circles indicate normalized reflectivity data from the surface of the $\mathrm{Au}_{82} \mathrm{Si}_{18}$ eutectic alloy for three temperatures $635 \mathrm{~K}$ (LT), 695 (HT), and 720 (LL). ${ }^{20}$ The solid lines describe calculated reflectivity for models in which the surface is coated with ordered surface bilayers (LT), monolayers (FT), and a completely melted surface. ${ }^{20}$ 


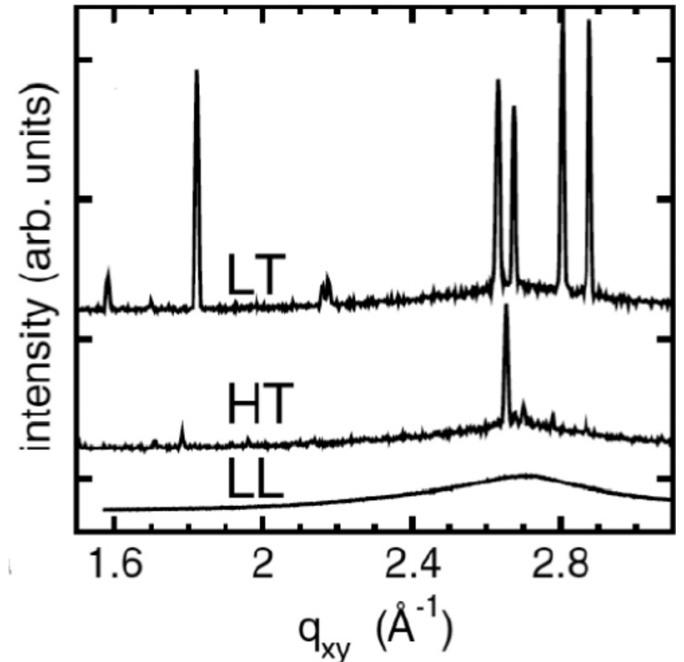

FIG. 4. Grazing incidence diffraction data from the surface of the $\mathrm{Au}_{82} \mathrm{Si}_{18}$ eutectic alloy at three different temperatures, $635 \mathrm{~K}$ (LT), 695 (HT), and 720 (LL). ${ }^{19,20}$ The sharp peaks observed for the LT and HT data indicate that at these temperatures the surfaces are crystalline, while the LL phase is liquid like. Truncation rod measurements establish that in the LT region the crystals are two-dimensional bilayers. These melt at $\sim 650 \mathrm{~K}$ to form two dimensional monolayer crystals.

the Debye-Waller process would otherwise have in reducing the reflected intensity from the LT phase. The weaker Debye-Waller effect accounts for the relatively large intensity of the LT reflectivity peak.

Aside from the surface freezing effect that was observed by Rice and colleagues for liquid $\mathrm{Ga}$ containing trace amounts of either $\mathrm{Tl}$ (Ref. 21) or Pb (Ref. 22) near coexistence with the bulk crystals of $\mathrm{Tl}$ and $\mathrm{Pb}$ the $\mathrm{Au}_{82} \mathrm{Si}_{18}$ eutectic was the only liquid metal that had been found at that time to exhibit the type of surface freezing just described. This leads to the question of what is special about $\mathrm{Au}_{82} \mathrm{Si}_{18}$ and raises the need to search for others alloys that show surface freezing.

The most obvious other system that seems like a good candidate for surface freezing is the $\mathrm{Au}_{72} \mathrm{Ge}_{28}$ eutectic. For example, the phase diagram of $\mathrm{Au}_{72} \mathrm{Ge}_{28}$ is almost identical to that of $\mathrm{Au}_{82} \mathrm{Si}_{18}$ and since the $\mathrm{Si}$ and Ge chemistry are also nearly identical one might have expected the two alloys would exhibit similar surface phenomena. They do not. The $\mathrm{Au}_{72} \mathrm{Ge}_{18}$ surface does not surface freeze. ${ }^{23}$

There is one difference between the $\mathrm{Si}$ and Ge eutectics that suggests a clue to the surface freezing effect. Although $\mathrm{Au}_{82} \mathrm{Si}_{18}$ is known to form an amorphous solid phase (i.e., a glass) on rapid cooling ${ }^{24}$ the $\mathrm{Au}_{72} \mathrm{Ge}_{28}$ liquid does not. ${ }^{25}$ The precise explanation for why some alloys are good glass formers while other are not is not fully understood; however, it does appear as though the good glass formers all have a composition near a deep eutectic and a large negative heat of mixing. In addition, it appears as though they all have well developed short-range order that is often in the form of icosahedral packing. ${ }^{26-29}$ One suggestion is that the icosahedral packing inhibits formation of the bulk crystalline phase on cooling. ${ }^{30}$ Mechler et al. suggested that surface freezing and glass formation might have a common origin. ${ }^{31}$ The idea according to this line of thought is that the surface freezing effect is somehow associated with the constraint that the surface imposes on the short-range order of the bulk liquid. Unfortunately, surface freezing of the type observed in $\mathrm{Au}_{82} \mathrm{Si}_{18}$ was not also found in any of the following four Pd-based eutectics $\mathrm{Pd}_{82} \mathrm{Ge}_{18}, \quad \mathrm{Pd}_{53} \mathrm{Ge}_{47}, \mathrm{Pd}_{36} \mathrm{Ge}_{64}$, or $\mathrm{Pd}_{85.1} \mathrm{Si}_{14.9}$, all of which are good glass forming liquids. ${ }^{32}$ On the other hand, the idea that surface freezing and glass forming are related is supported by the observation that surface freezing like that in $\mathrm{Au}_{82} \mathrm{Si}_{18}$ has been found in the glass forming alloy $\mathrm{Au}_{49} \mathrm{Cu}_{26.9} \mathrm{Si}_{16.3} \mathrm{Ag}_{5.5} \mathrm{Pd}_{2.3}{ }^{31}$ This is clearly an issue that requires further investigation.

There is yet a third type of surface order that has been observed in addition to the simple surface layering (Figs. 1-3) and surface freezing (Fig. 4). The effect can be seen in the low angle reflectivity measurement of $\mathrm{Pd}_{82} \mathrm{Ge}_{18}$, which is shown in Fig. $5{ }^{32}$ The inset to Fig. 5 shows the full range of $\mathrm{q}_{\mathrm{z}}$ over which the reflectivity was measured. There is no evidence for the interference maxima around $\mathrm{q}_{\mathrm{z}} \approx 2.0-2.5 \AA^{-1}$ that is characteristic of atomic size surface layering. On the other hand, there are well developed oscillations in the reflectivity at small $\mathrm{q}_{\mathrm{z}}$ that can be modeled by $\sim 40 \AA$ surface layer with an average electron density that is about $4 \%$ larger than the average electron density in the bulk of the alloy.

This is the only metal for which this type of low angle oscillation has been observed; however, the literature contains many instances in which liquid metal alloys are known to form nano-meter scale atomic clusters. ${ }^{33}$ Although there is not any data to confirm $\sim 40 \AA$ scale clusters in liquid $\mathrm{Pd}_{82} \mathrm{Ge}_{18}$ the idea that such clusters exist and segregate to the surface is the only explanation that we have been able to think of that might explain these low angle oscillations.

Finally, the last type of surface effect that we wish to discuss deals with chemical reactions at surfaces. The upper portion of Fig. 6 compares the results of a grazing incidence scattering measurement from the clean surface of liquid Sn

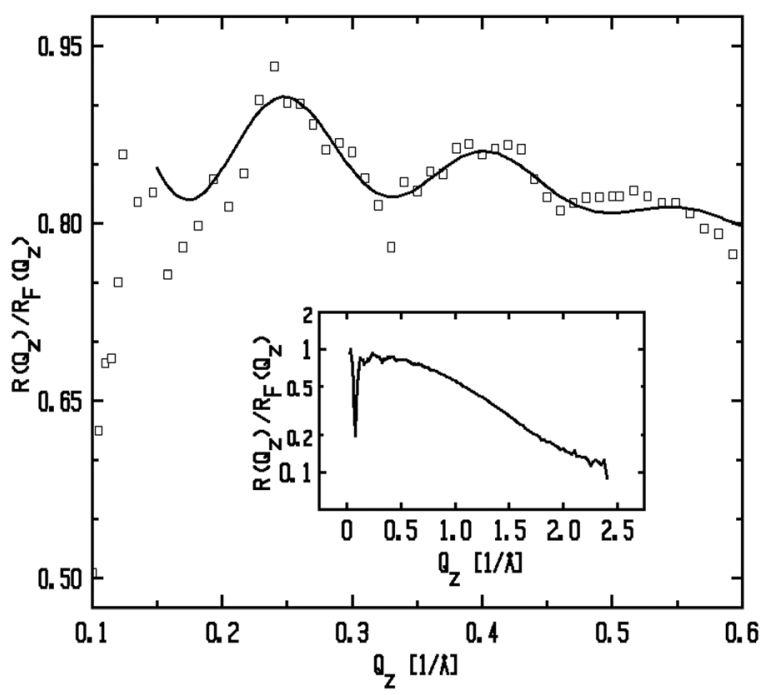

FIG. 5. $\mathrm{R}\left(\mathrm{q}_{\mathrm{z}}\right) / \mathrm{R}_{\mathrm{F}}\left(\mathrm{q}_{\mathrm{z}}\right)$ data for the $\mathrm{Pd}_{82} \mathrm{Ge}_{18}$ eutectic alloy. The inset shows the full range of the measured reflectivity while the main portion shows only the small angle portion. The solid line is a model reflectivity calculated from a $\sim 40 \AA$ surface layer with an average electron density $\sim 4 \%$ larger than the bulk liquid. ${ }^{32}$ 


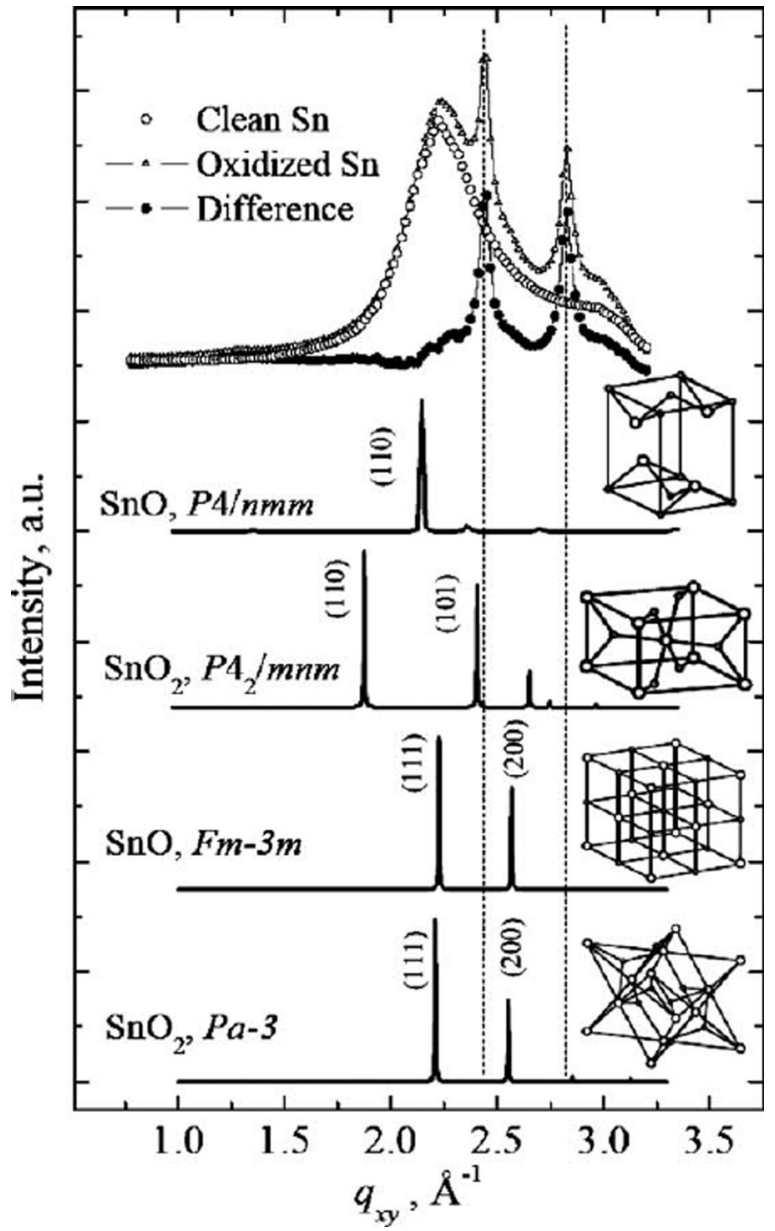

FIG. 6. (Top) Grazing incidence x-ray scattering results from the surface of clean liquid $\operatorname{Sn}(\bigcirc)$, from oxidized $\operatorname{Sn}(\triangle)$, and the difference $(\bullet)$. (Bottom four) Simulated powder diffraction data and structures for the only four known crystal phases of $\mathrm{SnO}$ and $\mathrm{SnO}_{2}$. Reprinted with permission from A. Grigoriev et al., Surf. Sci. 575, 223-232 (2005). Copyright 2005 Elsevier. ${ }^{34}$

(O) and a similar measurement after the surface has been exposed to low pressure $\mathrm{O}_{2}(\Delta)$. The two sharp peaks in the difference spectra $(0)$ are Bragg peaks from a 3D crystal powder pattern. ${ }^{34}$ Other measurements confirm that these are 3D powder diffraction peaks. The noteworthy thing about these peaks is that they are not the same as the power diffraction peaks from the four known $\mathrm{Sn}-\mathrm{O}$ phases whose diffraction patterns are shown in the lower portion of Fig. 6. The upper two of these form at ambient conditions, while the lower two only form at pressures about $21 \mathrm{GPa}$. As discussed in more detail by Grigoriev et al., the positions of the two peaks from the surface oxide, along with their relative intensities and the absence of any other peaks strongly implies that this surface oxide has the fcc rock salt structure. This would then be a previously unobserved phase of Sn-O.

\section{DISCUSSION}

As reviewed in this article, the atomic structure at the surface of liquid surfaces was completely unexplored prior to the early 1980s. At that time synchrotron x-ray sources made the novel liquid surface reflectometer that enabled structural measurements practical. ${ }^{6,35}$ In this article, we initially described the salient features of the x-ray specular reflectivity studies that were subsequently done on some of the elemental liquid metals. The first of these, on liquid Ga and $\mathrm{Hg}$ revealed the reflectivity peaks shown in Fig. 1 that demonstrated the expected surface induced atomic layering. ${ }^{4,5}$ The surprise in this data is the difference between the shapes of the reflectivity for $\mathrm{Ga}$ and $\mathrm{Hg}$.

As was mentioned above, a model in which the atomic layering induced by the surface decays monotonically with distance can explain data for liquid $\mathrm{Ga}$. In contrast, the measurement on $\mathrm{Hg}$ indicates that this is not the case for $\mathrm{Hg}$. The effect in $\mathrm{Hg}$ can be accounted for by a model proposed by Bomont et al. $^{7}$ in which three parameters representing the atomic-atomic interactions between atoms in the vapor, between atoms in the liquid and between atoms in the vapor and the liquid are different. In a separate approach, Calderín et al. ${ }^{17}$ carried out a different molecular simulation study to explain similar but subtler effects that can be seen for the surface layering of $\mathrm{Sn}$ and $\mathrm{Bi}^{13}$

Although it would be possible to measure a few additional metals the combination of high vapor pressure and the increased capillary exponent, $\eta$, for most of the other metals in the periodic table makes them virtually impossible to study. ${ }^{8}$ Consequently, there may never be enough data to establish an unambiguous explanation for the variations in the surface layering of elemental liquid metals.

On the other hand, there is a nearly inexhaustible supply liquid metal alloys that can be studied. One of the most interesting questions for these alloys is the origin of type of surface freezing that was shown in Fig. 4 for the $\mathrm{Au}_{82} \mathrm{Si}_{18}$ eutectic alloy ${ }^{19}$ and which was found again for the $\mathrm{Ag}-\mathrm{Cu}-$ Si-Ag-Pd glass forming alloy. ${ }^{31}$ In view of the fact that this type of surface freezing is not observed for $\mathrm{Au}_{72} \mathrm{Ge}_{28}$, which has a similar eutectic phase and similar chemistry to $\mathrm{Au}_{82} \mathrm{Su}_{18}$ but which does not form a metallic glass in the same way as $\mathrm{Au}_{82} \mathrm{Si}_{18}$, it is tempting to conclude that surface freezing is associated with the glass forming ability. This is one subject that needs further exploration.

Other phenomena that warrant further study are the small angle oscillations shown in Fig. 5 for the $\mathrm{Pd}_{82} \mathrm{Ge}_{18}$ alloy and the chemical effects like that shown in Fig. 6 for oxidation at the Sn surface. The first of these two effects was only observed in this one alloy. As proposed above, it is likely that it is caused by surface segregation of macroscopic ( $\sim 40 \AA$ ) atomic clusters of the type that are known to occur in other alloys. ${ }^{33}$

The observation that makes the oxidation study of the $\mathrm{Sn}$ surface interesting is that the oxide Sn-O crystals that form at the surface are different from all of the known Sn-O bulk phases. Although Bragg peaks were not found in the oxidized surface of liquid Ga the structure and temperature dependence in the reflectivity implied the existence of a $\sim 5 \AA$ this layer of solid Ga-O. ${ }^{36}$ The question is whether surface chemistry at liquid metal surfaces can result in new phases is a subject that needs further investigation.

Another possible line of line of experiments might be to analyze the $\mathrm{x}$-ray fluorescence as a function of incident energy for grazing incidence. For example, the concern that Shpyrko et al. had over the possibility that differences 
between the reflectivity $\mathrm{Sn}$ and previously studied Ga and In might have been caused by trace impurities was ruled out by the absence of characteristic fluorescence lines from anything aside from Sn. (See Fig. 7 of Shpyrko et al. ${ }^{12}$ ). In principle, the dependence of the fluorescence intensity at grazing incidence can be used as an EXAFS type measurement of the near neighbor local order within the liquid surface. This might be particularly useful in probing the near neighbor packing at the surface of an alloy like $\mathrm{Bi}_{43} \mathrm{Sn}_{57}$ in which the both $\mathrm{Bi}$ and $\mathrm{Sn}$ coexist within the same layer. The combination of data from this type of measurement with energy dependent reflectivity like that shown in Fig. 2 might well yield otherwise unavailable information on the surface structure.

\section{ACKNOWLEDGMENTS}

All of original experiments that were done by Harvard and referred to in this review were supported by the U.S. Department of Energy DOE, Office of Basic Energy Sciences, Division of Materials Sciences and Engineering under Award No. DE-FG02-88ER45379.

${ }^{1}$ M. P. D'Evelyn and S. A. Rice, "Structure in the density profile at the liquid-metal interface,” Phys. Rev. Lett. 47(25), 1844-1847 (1981).

${ }^{2}$ M. P. D'Evelyn and S. A. Rice, "A pseudoatom theory for the liquid-vapor interface of simple metals - Computer-simulation studies of sodium and cesium,” J. Chem. Phys. 78(8), 5225-5249 (1983).

${ }^{3}$ M. P. D'Evelyn and S. A. Rice, "A study of the liquid-vapor interface of mercury - Computer-simulation results," J. Chem, Phys. 78(8), 5081-5095 (1983).

${ }^{4}$ M. J. Regan et al., "Surface layering in liquid gallium: X-ray reflectivity study," Phys. Rev. Lett. 75, 2498-2501 (1995).

${ }^{5} \mathrm{O}$. M. Magnussen et al., "X-ray reflectivity measurements of surface layering in liquid mercury," Phys. Rev. Lett. 74, 4444-4447 (1995).

${ }^{6} \mathrm{P}$. S. Pershan and J. Als-Nielsen, "X-ray reflectivity from the surface of a liquid crystal: Surface structure and absolute value of critical fluctuations," Phys. Rev. Lett. 52, 759 (1984).

${ }^{7}$ J. M. Bomont et al., "Computer simulation calculations of the free liquid surface of mercury," Phys. Rev. B 79(14), 144202 (2009).

${ }^{8}$ P. S. Pershan and M. Schlossman, Liquid surfaces and Interfaces: Synchrotron X-ray methods (Cambridge, UK, 2012).

${ }^{9} \mathrm{M}$. Regan et al., "Capillary-wave roughening of surface-induced layering in liquid gallium," Phys. Rev. B 54, 9730-9733 (1996).

${ }^{10} \mathrm{H}$. Tostmann et al., "Surface structure of liquid metals and the effect of capillary waves: X-ray studies on liquid indium,” Phys. Rev. B 59, 783-791 (1999).

${ }^{11}$ O. G. Shpyrko et al., "X-ray study of the liquid potassium surface: Structure and capillary wave excitations," Phys. Rev. B 67, 115405 (2003).

${ }^{12}$ O. G. Shpyrko et al., "Anomalous layering at the liquid Sn surface," Phys. Rev. B 70, 224206 (2004).
${ }^{13}$ P. S. Pershan et al., "Surface structure of liquid Bi and Sn: An x-ray reflectivity study," Phys. Rev. B 79, 115417 (2009).

${ }^{14} \mathrm{~S}$. Mechler et al., "X-ray measurements of the surface of liquid Ge" (unpublished).

${ }^{15}$ D. K. Schwartz et al., "Thermal diffuse scattering studies of the watervapor interface," Phys. Rev. A 41, 5687-5690 (1990).

${ }^{16} \mathrm{E}$. DiMasi et al., "X-ray reflectivity study of temperature dependent surface layering in liquid Hg," Phys. Rev. B 58, 13419-13422 (1998).

${ }^{17}$ Calderín, L., L. E. González, and D. J. González, "First-principles study of the layering at the free liquid Sn surface," Phys. Rev. B 80, 115403 (2009).

${ }^{18}$ O. G. Shpyrko et al., "Atomic-scale surface demixing in a eutectic liquid BiSn alloy,” Phys. Rev. Lett. 95, 106103 (2005).

${ }^{19}$ O. G. Shpyrko et al., "Surface crystallization in a liquid AuSi alloy," Science 313(5783), 77-80 (2006).

${ }^{20} \mathrm{~S}$. Mechler et al., "Self consistent interpretation of the 2D structure of the liquid $\mathrm{Au}_{82} \mathrm{Si}_{18}$ surface: Bending rigidity and the Debye-Waller effect," Phys. Rev. Lett. 105, 186101 (2010).

${ }^{21}$ B. Yang, D. X. Li, and S. A. Rice, "Two-dimensional freezing of $\mathrm{Tl}$ in the liquid-vapor interface of dilute Tl in a Ga alloy," Phys. Rev. B 67(21), 212103 (2003).

${ }^{22} \mathrm{~B}$. Yang et al., "Two-dimensional freezing in the liquid-vapor interface of a dilute $\mathrm{Pb}$ :Ga alloy," PNAS 96, 13009-13011 (1999).

${ }^{23}$ P. S. Pershan et al., "Surface structure of the liquid $\mathrm{Au}_{72} \mathrm{Ge}_{28}$ eutectic phase: X-ray reflectivity,” Phys. Rev. B 80, 125414 (2009).

${ }^{24}$ W. Klement, R. H. Willens, and P. Duwez, "Non-crystalline structure in solidified gold-silicon alloys," Nature 187(4740), 869-870 (1960).

${ }^{25}$ R. Ramachandrarao and T. R. Anantharanab, "New metastable phases in silver-germanium and gold-germanium alloys quenched from the melt," Trans. Metall. Soc. AIME 245, 886-887 (1969).

${ }^{26} \mathrm{H}$. W. Sheng et al., "Atomic packing and short-to-medium-range order in metallic glasses," Nature 439(7075), 419-425 (2006).

${ }^{27} \mathrm{~A}$. Pasturel et al., "Structural and dynamic evolution in liquid Au-Si eutectic alloy by ab initio molecular dynamics," Phys. Rev. B 81(14), 140202 (2010).

${ }^{28} \mathrm{~S}$. Mechler et al., "Local structure and site substitution in amorphous and quasicrystalline Zr-Ti-Ni-(Cu) alloys," Appl. Phys. Lett. 97(4), 041914 (2010).

${ }^{29}$ Y. T. Shen et al., "Icosahedral order, frustration, and the glass transition: Evidence from time-dependent nucleation and supercooled liquid structure studies," Phys. Rev. Lett. 102(5), 057801 (2009).

${ }^{30}$ F. C. Frank, "Supercooling of liquids," Proc. R. Soc. London, Ser. A 215(1120), 43-46 (1952).

${ }^{31}$ S. Mechler et al., "Crystalline monolayer surface of liquid Au-Cu-Si-Ag-Pd: Metallic glass former," Appl. Phys. Lett. 98, 251915 (2011).

${ }^{32}$ S. Mechler et al., "Surface structure of Pd-Ge and Pd-Si liquid alloys" (unpublished).

${ }^{33}$ K. Urban and M. Feuerbacher, "Structurally complex alloy phases," J. Non-Cryst. Solids 334-335, 143-150 (2004).

${ }^{34}$ A. Grigoriev et al., "Surface oxidation of liquid Sn," Surf. Sci. 575, 223-232 (2005).

${ }^{35}$ J. Als-Nielsen, F. Christensen, and P. S. Pershan, "Smectic-A order at the surface of a nematic liquid crystal: Synchrotron x-ray diffraction," Phys. Rev. Lett. 48, 1107 (1982).

${ }^{36}$ M. J. Regan et al., "Oxidation of liquid gallium surfaces: X-ray reflectivity study,” Phys. Rev. B 55, 10786-10790 (1997). 